\title{
EFEITO DO TRATAMENTO TÉRMICO NAS PROPRIEDADES FÍSICO- QUÍMICAS DA POLPA DE UMBU
}

\author{
$\underline{\text { Gabriella Freitas de Jesus }}{ }^{1}$; Ernesto Acosta Martinez²; Silvia Maria Almeida de \\ Souza $^{3}$
}

1. Bolsista PROBIC/UEFS, Graduando em Engenharia de Alimentos, Universidade Estadual de Feira de Santana, email: eng.gabriellafreitas@yahoo.com.br

2. Orientador, Departamento de Tecnologia, Universidade Estadual de Feira de Santana, e-mail: ernesto.amartinez@yahoo.com.br

3. Coordenadora do projeto, Departamento de Tecnologia, Universidade Estadual de Feira de Santana, e-mail: $\underline{\text { ss_almeida@yahoo.com.br }}$

PALAVRAS-CHAVE: umbu; pasteurização; processamento.

\section{INTRODUÇÃO}

O umbuzeiro (Spondias tuberosa Arruda Camara) é uma planta de múltiplos usos, servindo para alimentação de animais domésticos, silvestres e do próprio homem. É encontrada em toda a região do polígono das secas no Brasil (Araújo \& Calvacanti, 2000). O extrativismo dos frutos é uma importante fonte de renda e de absorção de mão de obra para as famílias rurais da região semiárida. A colheita dos frutos é feita manualmente e a comercialização é realizada diretamente com os atravessadores nas comunidades que fazem o extrativismo do umbu, nas margens das rodovias e nas feiras livres. Pela ausência de cultivo comercial, são poucos os estudos que tratam do rendimento dos frutos. Em condições de vegetação espontânea, as estimativas são muito variadas, dependendo da idade da planta, da variabilidade genética e do ambiente. A produção pode variar de 65 a 300 quilos de frutos por planta (Araújo et al., 2000). Na época da safra, que vai de dezembro a março, há fartura de frutos e, durante a colheita, ocorre perda considerável de umbu maduro por ser bastante perecível. Como consequência, surgiu a necessidade do desenvolvimento de tecnologia apropriada para o aproveitamento de toda a produção e diminuição de perdas para o produtor, além da agregação de valor aos produtos derivados (Policarpo et al., 2003). Este trabalho objetiva avaliar o efeito da temperatura e do tempo de pasteurização nas propriedades da polpa de umbu.

\section{MATERIAL E MÉTODOS}

Os umbus foram obtidos no Centro de Abastecimento de Feira de Santana foram selecionados, lavados, sanitizados com solução clorada (200 ppm) por $20 \mathrm{~min}$ e enxaguados com água filtrada. As polpas foram obtidas em despolpadeira Itametal 165, acondicionadas em sacos de polietileno, embaladas a vácuo e armazenadas sob temperatura de congelamento.

A pasteurização (temperatura entre $59,87^{\circ} \mathrm{C}$ e $95^{\circ} \mathrm{C}$ e tempo entre $17 \mathrm{~min}$ e $60 \mathrm{~min}$ ) foi realizada em frascos Erlenmeyer de $125 \mathrm{~mL}$ contendo $35 \mathrm{~g}$ de polpa em banho Maria, de acordo com ensaios do planejamento fatorial $2^{2}$ completo com três repetições do ponto central (Rodrigues \& Iemma, 2005). Após o ensaio o frasco foi imerso em béquer com água gelada contendo gelo. As amostras foram mantidas sob congelamento para as análises físico-químicas; $\mathrm{pH}$, concentração de sólidos solúveis( ${ }^{\circ}$ Brix $)$, acidez total e vitamina C (Instituto Adolfo Lutz, 2008) e proteínas (Galvani \& Gaertner, 2006). A análise estatística dos resultados foi realizada através de análise de variância e da superfície de resposta foi realizada utilizando o programa computacional Statistica 7.0. 


\section{RESULTADOS E DISCUSSÃO}

As propriedades físico-químicas da polpa in natura e os valores reportados na literatura são apresentados na Tabela 1.

Tabela 1. Propriedades físico-químicas do umbu in natura e valores encontrados na literatura para polpa de umbu.

\begin{tabular}{|c|c|c|c|c|}
\hline Propriedade & Umbu in natura & Mattietto (2004) & Hikubo (2006)Us & $\begin{array}{l}\text { Bastos et al. } \\
\quad(2016)\end{array}$ \\
\hline Acidez total (\%) & $1,46 \pm 0,02$ & 1,39 & 1,95 & 1,88 \\
\hline $\begin{array}{l}\text { Sólidos solúveis } \\
\left({ }^{\circ} \text { Brix }\right)\end{array}$ & $9,2 \pm 0,00$ & 9,59 & 9,40 & 8,50 \\
\hline $\begin{array}{l}\text { Açúcares } \\
\text { redutores }(\%)\end{array}$ & $4,1 \pm 0,01$ & 3,63 & 3,22 & 4,96 \\
\hline $\begin{array}{l}\text { Açúcares não } \\
\text { redutores }(\%)\end{array}$ & $3,89 \pm 0,00$ & 1,03 & 1,89 & 3,56 \\
\hline $\begin{array}{l}\text { Carboidratos } \\
\text { totais }(\%)\end{array}$ & $8,6 \pm 0,01$ & 4,93 & 5,11 & 8,52 \\
\hline $\mathrm{pH}$ & $2,48 \pm 0,00$ & 2,93 & 1,70 & 2,42 \\
\hline Proteína (\%) & $1,34 \pm 0,01$ & 0,75 & 0,58 & 0,68 \\
\hline Vitamina C (\%) & $5,82 \pm 0,01$ & 23,83 & 5,40 & 5,47 \\
\hline
\end{tabular}

A polpa de umbu teve valores de acidez similares ao reportado por Mattietto (2004) porém valores menores que 1,95 e 1,88 reportados por Ushikubo (2006) e Bastos et al. (2016) respectivamente. As diferenças podem estar relacionadas com o estagio de maturação das frutas, região e processamento. O teor de sólidos solúveis da polpa $\left(9,2^{\circ}\right.$ Brix) foi similar aos valores reportados na literatura por Mattietto (2004) e Ushikubo (2006). Valores menores de sólidos solúveis (8,5 ${ }^{\circ}$ Brix) foram reportados por Bastos et al. (2016) para polpa de umbu comercial. Estas diferenças poderiam estar relacionadas com a adição eventual de água e pelo uso de aditivos e conservantes durante o processamento da polpa industrial para garantir maior tempo de vida de prateleira assim como devido a diferentes regiões, pontos de colheita e graus de maturação das frutas (Bastos et al., 2016). A polpa de umbu in natura teve um conteúdo de açúcares redutores $(4,1 \%)$ menor que 4,96\% reportado por Bastos et al. (2016) porém maior que 3,6\% e 3,2\% reportados por Mattietto (2004) e Ushikubo (2006), respectivamente. As concentrações de açúcares não redutores $(3,9 \%)$ e de carboidrato total $(8,6 \%)$ foram similares aos reportados por Bastos et al. (2016) que foram de 3,6\% e $8,5 \%$, respectivamente. Polpas com menores concentrações de açúcares não redutores $(1,0 \%$ e $1,9 \%)$ e carboidrato total $(4,9 \%$ e $5,1 \%)$ foram verificadas por Mattietto (2004) e Ushikubo (2006), respectivamente. Maiores concentrações de açúcares nas polpas de umbu in natura podem estar relacionados com o maior grau de maturidade dos frutos o qual resulta no aumento dos teores de açúcares porque as carboidrases presentes nos frutos vão degradando os polissacarídeos, convertendo-os em monossacarídeos e dissacarídeos. A polpa teve um $\mathrm{pH}$ igual a 2,48 similar a 2,75 e 2,42 reportados por Mattietto (2004) e Bastos et al. (2016), respectivamente. Polpa com menor $\mathrm{pH}(1,70)$ foi reportada por Ushikubo (2006). A legislação brasileira não estabelece padrão de qualidade para a polpa de umbu (Brasil, 2000). A concentração de proteína da polpa de umbu in natura $(1,34 \%)$ foi maior que as concentrações para as polpas de umbu reportadas na literatura. Isto pode ser devido às condições do ambiente pré-colheita tais como: clima e temperatura e influencias do cultivo como o tipo de solo, suprimento de água e nutrientes. A concentração de vitamina $\mathrm{C}(5,8 \%)$ foi similar aos valores reportados por Ushikubo (2006) e Bastos et al. (2016). Polpa com maior concentração de vitamina C $(23,8 \%)$ foi reportada por Mattietto (2004).

Na Tabela 2 são apresentadas as propriedades físico-químicas da polpa de umbu após cada ensaio de pasteurização. 
Tabela 2. Caracterização físico-química das polpas de frutas após a pasteurização.

\begin{tabular}{ccccccccc} 
Ensaio & $\begin{array}{c}\text { Acidez } \\
\text { total }(\boldsymbol{\%})\end{array}$ & S.S. $\left({ }^{\mathbf{o}} \mathbf{B r i x}\right)$ & $\mathbf{A R}(\boldsymbol{\%})$ & ANR (\%) & $\mathbf{C C T}(\boldsymbol{\%})$ & $\mathbf{p H}$ & $\begin{array}{c}\text { Proteínas } \\
(\boldsymbol{\%})\end{array}$ & $\begin{array}{c}\text { Vitamina } \\
\mathbf{C}(\boldsymbol{\%})\end{array}$ \\
\hline 1 & $2,38 \pm 0,01$ & $7,4 \pm 0,00$ & $8,7 \pm 0,02$ & $20,4 \pm 0,00$ & $29,1 \pm 0,02$ & $2,21 \pm 0,00$ & $0,72 \pm 0,01$ & $0,7 \pm 0,02$ \\
2 & $2,28 \pm 0,09$ & $11,6 \pm 0,00$ & $8,1 \pm 0,02$ & $9,5 \pm 0,07$ & $17,1 \pm 0,01$ & $2,43 \pm 0,00$ & $0,96 \pm 0,01$ & $0,7 \pm 0,01$ \\
3 & $2,07 \pm 0,01$ & $8,1 \pm 0,00$ & $8,1 \pm 0,17$ & $7,6 \pm 0,10$ & $15,7 \pm 0,02$ & $2,5 \pm 0,00$ & $1,05 \pm 0,01$ & $1,0 \pm 0,03$ \\
4 & $1,6 \pm 0,02$ & $7,9 \pm 0,00$ & $6,1 \pm 0,01$ & $6,8 \pm 0,07$ & $12,9 \pm 0,02$ & $2,48 \pm 0,00$ & $1,10 \pm 0,02$ & $1,2 \pm 0,02$ \\
5 & $2,32 \pm 0,02$ & $8,0 \pm 0,00$ & $8,5 \pm 0,02$ & $9,4 \pm 0,07$ & $17,9 \pm 0,01$ & $2,42 \pm 0,00$ & $0,76 \pm 0,02$ & $0,7 \pm 0,01$ \\
6 & $2,31 \pm 0,02$ & $8,0 \pm 0,00$ & $8,7 \pm 0,01$ & $15,9 \pm 0,07$ & $24,6 \pm 0.02$ & $2,41 \pm 0,00$ & $0,76 \pm 0,02$ & $0,5 \pm 0,01$ \\
7 & $2,31 \pm 0,02$ & $8,1 \pm 0,00$ & $8,7 \pm 0,01$ & $17,9 \pm 0,07$ & $26,6 \pm 0,02$ & $2,39 \pm 0,00$ & $0,86 \pm 0,023$ & $0,5 \pm 0,01$ \\
8 & $2,11 \pm 0,01$ & $8,2 \pm 0,00$ & $8,5 \pm 0,025$ & $38 \pm 0,15$ & $46,5 \pm 0,03$ & $2,38 \pm 0,00$ & $0,72 \pm 0,01$ & $0,87 \pm 0,02$ \\
9 & $2,81 \pm 0,02$ & $8,0 \pm 0,00$ & $8,7 \pm 0,01$ & $22,3 \pm 0,07$ & $31,7 \pm 0,02$ & $2,47 \pm 0,00$ & $0,86 \pm 0,01$ & $1,31 \pm 0,01$ \\
10 & $1,77 \pm 0,01$ & $8,0 \pm 0,00$ & $8,1 \pm 0,01$ & $9,7 \pm 0,00$ & $17,8 \pm 0,01$ & $2,43 \pm 0,00$ & $0,81 \pm 0,01$ & $0,65 \pm 0,01$ \\
11 & $1,71 \pm 0,01$ & $8,2 \pm 0,00$ & $7,2 \pm 0,02$ & $3,9 \pm 0,07$ & $11,1 \pm 0,01$ & $2,44 \pm 0,00$ & $1,1 \pm 0,03$ & $0,87 \pm 0,02$ \\
\hline
\end{tabular}

Onde: S.S.= Sólidos Solúveis, $\mathrm{AR}=$ Açúcares Redutores, ANR.= Açúcares não Redutores, CCT= carboidratos totais.

Na Figura 1 apresentam-se as superfícies de resposta para a acidez total (AT), açúcares redutores (AR), carboidratos totais (CCT), $\mathrm{pH}$ e vitamina $\mathrm{C}$ da polpa de umbu in natura em função da temperatura $(\mathrm{T})$ e do tempo $(\mathrm{t})$ de pasteurização.

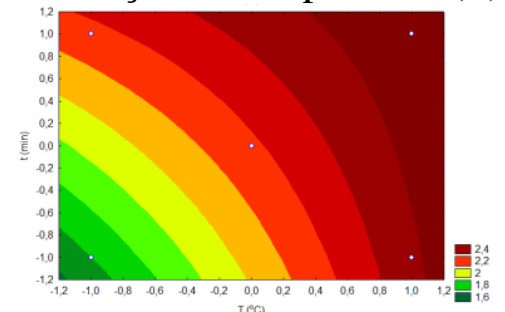

A

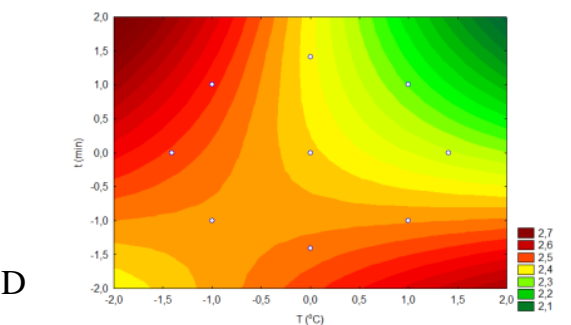

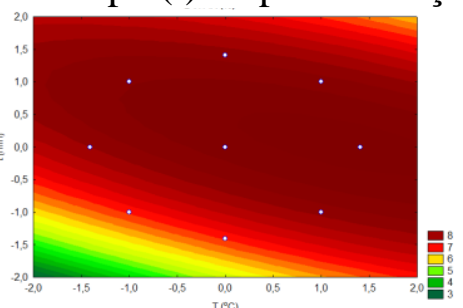

B

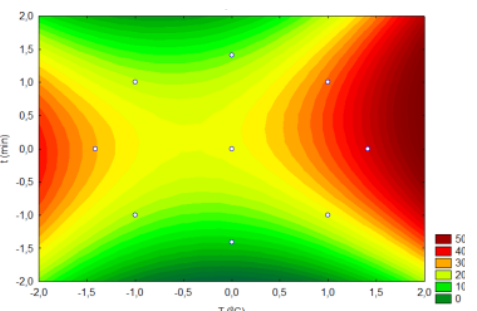

$\mathrm{C}$

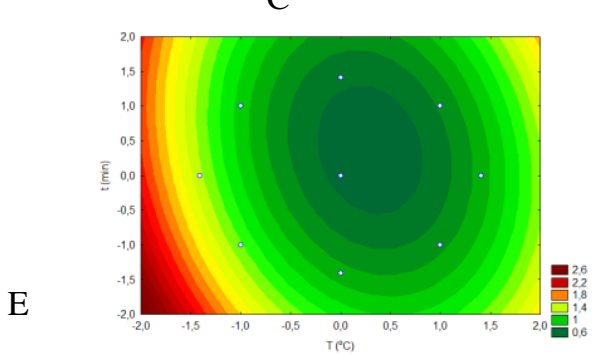

Figura 1: Superfícies de resposta para: A. a acidez total (AT), B. açúcares redutores (AR), C. concentração de carboidratos totais (CCT), D. pH e E. vitamina C da polpa de umbu in natura em função da temperatura $(\mathrm{T})$ e do tempo (t) de pasteurização A.

Com base nos resultados obtidos, considerando os termos significativos, e com auxílio da metodologia de superfície de resposta, obteve-se um modelo matemático para representar as respostas acidez total (AT) (Eq. 1), teor de sólidos solúveis (S.S.) (Eq. 2); açúcares redutores AR (Eq. 3); concentração de carboidratos totais (CCT) (Eq. 4), pH (Eq. 5) e concentração de vitamina $\mathrm{C}$ na polpa de umbu in natura (Eq. 6).

$$
\begin{array}{lcc}
\mathrm{AT}=2,185+0,495 \mathrm{~T}+0,285 \mathrm{t}-0,185 \mathrm{~T} \mathrm{X} \mathrm{t} & \mathrm{R}^{2}=0,7977 & \text { Eq. } 1 \\
\mathrm{~S} . \mathrm{S} .=8,443+1,5 \mathrm{~T}-2,0 \mathrm{t}-2,2 \mathrm{~T} X \mathrm{t} & \mathrm{R}^{2}=0,9259 & \text { Eq. } 2 \\
\mathrm{AR}=8,635+0,58 \mathrm{~T}+0,97 \mathrm{t}-1,18 \mathrm{t}^{2}-0,7 \mathrm{~T} \mathrm{X} \mathrm{R} \mathrm{R}^{2}=0,7628 & \text { Eq. } 3 \\
\mathrm{CCT}=23,06+9,77 \mathrm{~T}+12,12 \mathrm{~T}^{2}-12,67 \mathrm{t}^{2} & \mathrm{R}^{2}=0,8378 & \text { Eq. } 4 \\
\text { pH }=2,41-0,12 \mathrm{~T}-0,0512,12 \mathrm{~T}-0,12 \mathrm{~T} \mathrm{X} \mathrm{t} \quad \mathrm{R}^{2}=0,8042 & \text { Eq. } 5 \\
\text { Vit. } \mathrm{C}=0,566-0,342 \mathrm{~T}+0,523 \mathrm{~T}^{2} \quad \mathrm{R}^{2}=0,9425 & \text { Eq. } 6
\end{array}
$$

Onde: AT: acidez em ácido cítrico; teor de sólidos solúveis; S.S.; AR: açúcares redutores; CCT: concentração de carboidratos totais $\mathrm{T}$ : temperatura e t: tempo de pasteurização; Vit. C: concentração de vitamina C; T: temperatura, t: tempo. 
Pode-se constatar que maiores valores de AT na polpa de umbu (2,4 g ácido cítrico/100 g) são obtidos nas condições de maiores $\mathrm{T}\left(90{ }^{\circ} \mathrm{C}\right)$ e $\mathrm{t}(60 \mathrm{~min})$ de pasteurização (Figura 1A); maiores valores de AR na polpa de umbu in natura são obtidos nas condições de menor $\mathrm{T}$ e $\mathrm{t}$ de pasteurização e de maior $\mathrm{T}$ e $\mathrm{t}$ de pasteurização (Figura 1B); maiores valores de CCT (40\%) são obtidos em condições de pasteurização de maior temperatura (90 a $95{ }^{\circ} \mathrm{C}$ ) e tempo de pasteurização de $42,5 \mathrm{~min}$. (Figura $1 \mathrm{C}$ ); maiores valores de $\mathrm{pH}$ $(2,6)$ são obtidos em condições de pasteurização de maior temperatura $\left(90\right.$ a $\left.95{ }^{\circ} \mathrm{C}\right) \mathrm{e}$ menor tempo de pasteurização $(25 \mathrm{~min})$ ou com menor temperatura $\left(65^{\circ} \mathrm{C}\right)$ e maior tempo de pasteurização (60 min) (Figura 1D) e maiores valores de concentração de vitamina $C(1,4)$ são obtidos em condições de pasteurização de menores temperatura de pasteurização $\left(65^{\circ} \mathrm{C}\right)$ independentemente do tempo de pasteurização (Figura 1E). Na análise estatística para a resposta concentração de proteína na polpa de umbu in natura foi verificado que não houve efeito significativo das condições de temperatura e tempo de pasteurização.

\section{CONSIDERAÇÕES FINAIS}

A polpa de umbu in natura apresenta propriedades físico-químicas que permitem seu uso como matéria-prima na elaboração de outros produtos alimentícios. Maior acidez total na polpa é obtida nas condições de maior temperatura e tempo de pasteurização; maiores teores de sólidos solúveis com o uso de maior temperatura e menor tempo de pasteurização; maiores valores de açúcares redutores nas condições de menor temperatura e tempo de pasteurização; maiores valores de carboidratos totais em condições de maior temperatura e tempo de pasteurização intermediário; maiores valores de $\mathrm{pH}$ em condições de menor temperatura e maior tempo de pasteurização e maiores valores de concentração de vitamina $\mathrm{C}$ em condições de menor temperatura de pasteurização.

\section{REFERÊNCIAS}

ARAÚJO, F.P.; SANTOS, C.A.F.; CAVALCANTI, N.B. 2000. Cultivo do Umbuzeiro. Instruções Técnicas número 24. Embrapa Semi-árido: Petrolina - PE, 2000.

BASTOS, J. S.; MARTINEZ, E.A.; SOUZA, S.M.A. de. 2016. Características físico-químicas da polpa de umbu (Spondias tuberosa Arruda Camara) comercial: Efeito da concentração. Journal of Bioenergy and Food Science, 3(1):1-10, jan./mar.

BRASIL. 2000. Ministério da Agricultura, Pecuária e Abastecimento. Instrução Normativa no 01, de 07 de janeiro de 2000. Aprova o Regulamento técnico geral para fixação dos padrões de identidade e qualidade para polpa de fruta. Disponível em: <http://extranet.agricultura.gov.br>. Acesso em: 09 mar. 2011

INSTITUTO ADOLFO LUTZ. 2008. Normas Analíticas do Instituto Adolfo Lutz. Métodos químicos e físicos para análise de alimentos. 4. ed. São Paulo: IMESP.

MATTIETTO, R. A. 2005. Estudo Tecnológico de um Néctar Misto de Cajá (Spondias lútea L.) e Umbu (Spondias tuberosa Arruda Câmara). 2004. 299 f. Tese (Doutorado em Tecnologia de Alimentos). Universidade Estadual de Campinas, Campinas.

POLICARPO, V.M.N.; RESENDE, J.; ENDO, E.; MARCUSSI, B.; CASTRO, F.T.; JORGE, E.C.; BORGES, S.V.; CAVALCANTE, N.B. 2003. Aprovechamiento de la pulpa de "umbu" (Spondias tuberosa, Arr. Cam.) verde como alternativa para la producción de dulces en masa. Alimentaria, Madrid, 344:75-78.

RODRIGUES, M. I.; IEMMA, A. F. 2005. Planejamento de Experimentos e Otimização de Processos: uma estratégia sequencial de planejamentos, Campinas, SP, Casa do Pão Editora. USHIKUBO, F. Y. 2006. Efeito do tratamento enzimático, da velocidade tangencial e da pressão transmembrana na microfiltração da polpa diluída de umbu (Spondias tuberosa Arr. Cam). 2006. 117 p. Dissertação (Mestrado em Engenharia de Alimentos) - Universidade Estadual de Campinas, Campinas. 